\title{
Will smart pricing finally take off?
}

\author{
Andrew Odlyzko \\ School of Mathematics \\ University of Minnesota \\ Minneapolis, MN 55455, USA \\ odlyzko@umn.edu \\ http://www.dtc.umn.edu/ odlyzko \\ Revised version, October 20, 2013
}

\begin{abstract}
Smart pricing" has been the goal of the networking research community and the telecommunications industry for decades. Yet it has also proved remarkably hard to achieve. This paper presents a brief overview of telecommunications economics and technology, and the major changes that are taking place. Special emphasis is placed on the many popular but harmful notions that continue to lead this industry astray, such as that content is king, or that telecom is characterized by high fixed costs. The influence of such factors on advisability of various pricing strategies is then considered. The main conclusion is that flat rates for individual users should be regarded not as a pernicious cancer, but as necessary for the healthy development of wired networks. However, in the wireless arena, there is a mismatch between potential demand and what technology can provide, and this likely means that some forms of not-very-smart pricing will dominate.
\end{abstract}

\section{Introduction}

Will smart pricing dominate telecommunications? We certainly do see growth in sophisticated pricing in many areas of the economy. Congestion charges for cars entering central business districts and "smart" electric meter deployments are spreading. Airlines are even beginning to auction seat upgrades [31]. And there is no shortage of desire for smart pricing in telecommunications. For a survey of recent developments, see [58]. Many new technological developments, such as SDN, are touted as facilitating differentiated services and differentiated pricing. The overwhelming consensus of the industry, as well as of the research community, and of regulators, is that flat rates are irrational. Thus, for example, in 2011, Jon Leibowitz, the then-Chairman of the U.S. Federal Trade Commission could not "quite understand why something like metering hasn't taken off yet." (See [52] for references to this and similar recent quotes, as well as as for a summary of the arguments in favor of flat rates.)

Yet there are reasons for caution in the rush to smart pricing. After all, the modern consensus about its desirability is not new. It goes back centuries, to the days of snail mail. Furthermore, industry has often either stumbled onto flat or almost flat rates, or been forced into them, all against its will, and ended up benefiting. Thus, for example, U.S. 
wireless service providers have been boasting of the low per-minute voice call revenues that reign in America, much lower than in most of the world. What they universally neglect to mention is that these low prices are the result of the success of the block-pricing plan introduced by AT\&T Wireless in 1998, which also eliminated roaming and long-distance charges. This plan, the result not of a careful study of historical precedents or the economics of communications, but rather the fruit of a desperate carrier looking for a way to gain customers, was widely derided, but proved unexpectedly popular. It forced the rest of the industry to follow suit with similar plans, and led to large increases in voice usage (see the chart in [27], for example). The end result is that U.S. has the world's highest per-subscriber voice usage, yielding those low average per-minute prices that the industry boasts of. Probably not coincidentally, U.S. wireless service providers are among the world's most profitable. This story, and others like it, should make one cautious about rushing to follow the industry consensus. This is true even when such a consensus is fortified by scholarly studies, since those tend to be even more biased towards fine-grained pricing. The telecom industry and telecom researchers have historically been notorious for not understanding what is in the industry's own interests.

The traditional preoccupation with smart pricing is likely reinforced by the economics of telecom. Contrary to common opinion, it is not all that capital intensive. As is demonstrated in Section 8, telecom is simply not in the same category as such large and important industries as electricity or roads when it comes to the ratio of capital investment to revenues. Telecom is primarily about service, customer inertia, and territorial strategic plays (where the territories may be physical or virtual).

Although the telecom industry is not very capital intensive, communications is extremely valuable, and society is willing to pay astonishing amounts for it. As an example, by some measures the U.S. spends almost $50 \%$ more on telecom services than it does for electricity. (See Section 5 for more data and references.) Furthermore, in spite of all the complaints from the industry about its supposedly impoverished state, there appear to be very large profits in many parts of it. As this passage is being written in the summer of 2013, Verizon is in the process of buying out Vodafone's $45 \%$ stake in the Verizon Wireless unit for $\$ 130$ billion. This means that the whole of Verizon Wireless is being valued at almost $\$ 300$ billion. As will be shown in Section 9, that is about four times the cost of replacing all the tangible assets of that enterprise. It is also almost enough to replace the entire U.S. telecom infrastructure, wireless and wired both, with the latter redone in fiber. This is anomalous by traditional standards, but then, as will be discussed in Section 9, the entire economy is behaving anomalously, with very high corporate profits, low interest rates, and low capital investment. Whether this is a temporary aberration, or whether we are in a new economic era, remains to be seen. However, telecom is very much in the mainstream of this historically unusual behavior, so many traditional yardsticks of financial performance may not apply.

While the telecom industry has often been blind to profitable opportunities, it has always been aware that high profits are possible. However, it has usually faced difficulties in using their favorite methods for profit extraction because of various combinations of legal and regulatory constraints, and the peculiar nature of demand for communication services. 
Table 1 shows an approximation of current prices paid by users for varying amounts of data from various services.

Table 1. Price per megabyte.

$\begin{array}{lr}\text { SMS } & \$ 1,000.00 \\ \text { cellular voice } & 1.00 \\ \text { wireline voice } & 0.10 \\ \text { residential Internet } & 0.01 \\ \text { backbone Internet } & 0.0001\end{array}$

This table demonstrates the main problem faced by telecom. The most valuable information can often be conveyed in just a few bits. Thus, for example, in the early days of postal services, when receivers paid on delivery, information would often be transmitted in the form of small modifications in the address. The addressee would then scan the envelope, figure out what the message was, and refuse to accept (and pay for) the letter.

Practices from two centuries ago may seem irrelevant, but in fact they are very instructive to study, as the basic economic issues have always been the same, even as technology has changed drastically, cf. [41]. Thus, for example, today we have the telecom industry investing heavily in Deep Packet Inspection. In the past, post offices had employees hold letters up against burning candles, to make sure that there were no enclosures that were subject to extra fees. The basic incentive is to extract as much value as possible, and that usually requires fine-grained pricing to achieve successful price discrimination. But usually, in communication as well as in transportation, limits are placed on what service providers are allowed to do. The Net Neutrality debate is just another instance of the ancient conflict between economic efficiency and fairness in markets [50]. Giving unfettered control of any critical service to any provider, or an oligopoly of providers, either de jure or de facto (by allowing natural monopoly mechanisms to operate), is equivalent to abolishing property rights with the usual negative impacts on innovation and efficiency. Hence we have almost always had constraints, such as those of common carriage. The real question is about the appropriate level of constraints.

Public talk of capacity limits is often just a public relations measure, designed to overcome opposition to service provider strategies. Thus, for example, in early 2013, Michael Powell, the President of the U.S. cable industry association (and former Chairman of the FCC) admitted, contradicting many earlier declarations by a variety of executives and experts, that "cable's interest in usage-based pricing was not principally about network congestion, but instead about pricing fairness" [9]. Whenever business leaders talk of "fairness," it is generally safe to assume they are really after extracting more revenues through differential pricing. This is not novel, nor is it nefarious. In fact, differential pricing was and is at the core of regulatory economics, as it can be used to promote social welfare, and 
has frequently been mandated by governments. However, historically the degree of price discrimination that was allowed varied depending on economics, with more discrimination allowed when the costs of providing those services have been large [47]. The question for the near future is whether modern telecom should be allowed more power to discriminate. Further, even if it is given that power, one should consider whether it would be wise to use it. The right answer depends on the balance between growth in demand and improvements in technology.

The main problem, past, present, and future, that is faced by telecom is that the most valuable information usually requires just a few bits to convey. The second main problem is that due to technological progress, transmission capacity is growing. Thus the industry is faced with the challenge of persuading users to pay for big pipes when the additional value that enlarging those pipes provides is not all that high. (There are arguments that the value of transmission capacity, as well as of computing power and storage, should be measured on a logarithmic scale, so that going from what is now a slow 1 Mbps link to a 1 Gbps one corresponds only to an increase in value from 6 to 9, cf. [51].) At the moment, that additional capacity is consumed largely by video. But the value is still dominated by the low-bandwidth voice and texting.

The general conclusion of this work, based on study of trends in demand and supply, is that in wireline communication, the critical issue facing the telecom industry is not handling overpowering exafloods of traffic, as has often been claimed, cf. [14,60,61], but stimulating demand to fill the growing capacity of transmission systems [48]. The most effective way to do that is to offer flat rates and open access to encourage innovation. To the extent that any market segmentation is needed, it is best handled by offering flat rate services with different peak speeds. Pricing by volume of traffic (whether using caps or other schemes) may be attractive at the moment to service providers preoccupied with trying to protect their traditional subscription video service revenues. However, it is a blunt instrument that does not address any of the issues well, and in the long run is likely to damage not only the economy as a whole, but profits of service providers. Any truly "smart pricing" measures, such as congestion charges, are likely to be detrimental to the industry.

These general conclusions for wired communications apply directly mainly to the richer and more industrialized countries. Even in those, there will likely always be exceptional situations where the cost structure forces some "smart pricing" approaches. For poor countries, the best choices along the frontier of feasible technological and business models will likely lean further towards "smart pricing." This would be consistent with the general observation, cf. [41], that at the consumer level, sophisticated pricing is most appropriate for large and relatively infrequent transactions, and simple pricing for small and frequent ones. That is also what we observe in the market today, with the greatest proliferation of "smart pricing" in less-developed countries, where the relative burden of telecommunications charges is higher.

In wireless, the optimal choice even in rich countries appears to be different than for wireline, because of a different balance between feasible supply and potential demand. There have been widespread projections that wireless data traffic would continue to double each year, as it had done for a several years. Those are now being disproved, as growth rates 
are declining. (See Section 13.) Still, those rates are high, and there is far more traffic that would likely use the radio path if that were feasible, as wireless data traffic is under $5 \%$ of wireline. Coupled with the low value of most of this data, and the resulting low likelihood of service providers being able to extract large new revenues, it appears probable that the incentives for the industry will be to constrain usage, and to implement differentiated quality of service to protect the most valuable low-bandwidth applications. So somewhat finer-grained pricing is likely to prevail in this domain than in wireline. Still, the need to limit what Nick Szabo [62] has aptly called the "mental transaction costs" involved in finegrained pricing, and related concerns, are likely to restrict the complexity of schemes that succeed. The sophisticated pricing plans so beloved of researchers are likely to be confined to areas such as business-to-business dealings, and may be of limited applicability even there.

However, the strong prejudice in favor of "smart pricing" among both industry leaders and academic researchers guarantees that many schemes will be developed, and quite a few will be deployed. Chances are that, as was true of many sophisticated prioritization schemes developed for voice PBXs or early data switches, they will not see much use. But for those cases where they might be used, it appears that most of current research, as well as academic instruction is missing some important ingredients. As is discussed in Section 12 , it will likely be important to explore the most effective ways to introduce noise and other impairments into communication systems to provide differential quality of service. (On the other hand, there will likely also be demand for methods to detect such actions.)

The next section reviews briefly some of the main fallacies that invigorate the push for "smart pricing." This is followed by a section on some missed opportunities in telecom, demonstrating how this industry tends to "stumble to success," pursuing mistaken goals and prospering by accident. Section 4 then has a very brief discussion of the reasons telecom has been so poor at innovating in services, and is likely to remain poor in the future. Section 5 discusses this industry's place in the entire economy. Section 6 points out that high profits have not infrequently been obtained in this sector. Section 7 sketches the main changes that have taken place in the money flows in telecommunications in recent decades. Section 8 demonstrates that, contrary to general opinion, this industry is not all that capital intensive. Section 9 discusses some of the puzzles of the modern economy, and the degree to which the telecom industry exhibits similar behavior. Section 12, cited above, discusses some missing ingredients in modern research and education, should "smart pricing" become widespread. Sections 10 and 11 take a historical look at some earlier work on telecom pricing, and the degree to which it reflected the prejudices we observe today. Sections 13 and 14 then discuss growth in demand for data traffic and improvements in transmission technologies, and what the contrasts between those imply for optimal pricing strategies. Finally, Section 15 has the conclusions.

\section{Telecom mistakes}

Many of the basic but general issues that bear on the possible adoption of smart pricing have already been explored in the literature (see, for example, $[41,43,45,46]$ ), and so will be touched on very lightly here. However, they do need to be mentioned, since there are many 
misapprehensions about the nature of telecom, and they often have important bearing on optimal choices of pricing policies. For example, we are constantly told that content is king. (Content is taken here to mean material prepared by professionals for wide distribution, and not, as some use it, to denote anything in digital form.) But

\section{Content is not king.}

Yes, content, in the sense of material prepared by professionals for wide distribution, is important. But it is simply nowhere near as important as basic connectivity, and the revenues of various services reflect that. This is discussed in detail in [41,42]. Evidence of this fundamental fact is all around, and some will show up later in this paper (for example, in the observation that U.S. wireless carriers have revenues about three times as large as those that the cable industry derives from subscription video). However, content has historically attracted disproportionate attention, and continues to do so today. For example, an article in the Economist [7] stated:

A common saying in the industry is that Mexico's phone sector may be about four times more valuable than the television market, but the latter is four times as powerful.

What is especially perplexing about the centuries-old preoccupation with content is that content is not cheap. For telecom service providers to sell content, they generally have to buy it at high prices. (And so, net of what they pay to content producers, U.S. cable networks appear to be getting more revenue out of Internet access and voice services than out of carrying subscription video, and all on a far smaller slice of their transport capacity.) Back in 2005, Ed Whitacre, then the CEO of AT\&T, caused a flareup in the net neutrality debate with his threat that he would not let Google use his wires without payment. Strangely enough, it is not clear if anybody raised the question as to whether his basic premise was correct, that in the absence of any legal or regulatory constraint, it would be Google paying AT\&T. Why should not AT\&T have to pay Google? Perhaps Whitacre was right, and Bing might have been an acceptable substitute for Google search for AT\&T customers. But perhaps not. Imagine that Whitacre had said he was not going to let ESPN or HBO use AT\&T's U-Verse wires without payment. Instead of being called evil by small groups of advocates of an open Internet, he surely would have been called insane by almost everybody.

Because content is not king, the vast majority of papers and discussions about net neutrality, industry structure, and related issues are of doubtful relevance. For example, many academic papers start with the assumption that the Internet is a two-sided market. It simply is not. Most of the value that users get from it is not content, but simple connectivity, such as being able to tell their friends business partners they are stuck in traffic. Compared to old communication technologies, the Internet does provide many unique features, and in particular allows for bridging between content and connectivity. (The main search service of Google, which provides the bulk of that company's revenues and profits, but very little traffic, is in this intermediate zone, as are most of the facilities of social networks that users care about.) However, the features that matter the most are not the ones that allow content 
providers to target individual consumers, but the ones that allow for group formation, and for individuals or groups to become creators and distributors.

Closely allied to the misleading myth that content is king is another extremely widespread and extremely damaging notion, that of streaming video, [49]. However, all the evidence suggests that

True streaming video is, and will remain, a very small fraction of traffic.

Video does dominate current Internet traffic by volume, but it is almost exclusively transmitted as faster-than-real-time progressive downloads. That is the only method that makes sense technologically. (Video conferencing is completely different, but we now have enough experience to be able to predict with safety that it will not be contributing giant amounts of traffic.) Furthermore, this was easily predictable and was predicted a long time ago. George Gilder wrote about it two decades ago, for example, and he attributes the idea to Nicholas Negroponte even earlier. Their prediction has come true, yet almost everyone thinks that the floods of video they consume are true streaming video. This skewes business decisions and public policy discussions, since networks dominated by real-time long-lived data flows of predictable size and with tight latency constraints do indeed lend themselves to many of the pricing and network management techniques that are so beloved by both top managers and telecom researchers, cf. [40].

The myth of real-time streaming video is so pervasive and strong that it also affects networking researchers. For the last decade, this author has been taking polls asking those in the audience to raise their hands if they saw any advantage at all, for anyone, in transmitting video faster than real time. Usually, even among networking researchers, at most $10 \%$ have responded. The highest positive response rates were around 40\%, among a couple of audiences packed with researchers working on wireless ad-hoc networks, who understand that on connectivity being maintained, but can use buffers to compensate. (While one can envisage ultra-reliable wired networks, in the wireless arena this is simply not achievable, there are far too many unpredictable sources of impairments.) This demonstrates that even networking researchers don't know what is happening in today's networks, nor why it is happening.

The preoccupation with real-time streaming video leads to the constant questioning about the potential demand for high speed access. Who needs gigabit to the home, is being asked, since the most that most observers can imagine is a few streams that might possibly come to $20 \mathrm{Mbps}$ each in some future high-definition TV. This perfectly illustrates the lack of vision not just on the future, but on the present, that afflicts this industry. After all, why are people buying $300 \mathrm{Mbps}$ home $\mathrm{WiFi}$ access points, if all they are after is streaming a few movies? Yet such routers are selling, and high speed home access is also selling (when offered at reasonable cost), because they allow for low transaction latency.

The main function of data networks is to cater to human impatience.

This is something that the computer industry, as well as many other competitive industries, whether online search, or Internet commerce, understand well. If users don't get their web search results in a second, they go away. On the other hand, the telecom industry has a hard time assimilating this notion. Yet, if you want to download a video that is 8 GB to 
your portable device in less than a minute, you absolutely have to have a gigabit link. Hence

\author{
Overprovisioning is not a bug but a feature, as it indispensable \\ to provide low transaction latency, the main function of data networks.
}

Once you have overengineered your network, it becomes clearer that pricing by volume is not particularly appropriate, as it is the size and availability of the connection that creates most of the value. That is also what the users perceive directly. Generally speaking (and there are obviously exceptions, buffer bloat can lead to contrary experience), increased bandwidth means that things happen faster, the network is more responsive, etc. That is something that is immediately perceptible to users. It does not require them to engage in any mental transaction costs to figure out where they are with respect to violating some volume caps, for example.

In wireline, the vision of a largely empty network dominated (initially in value, eventually likely also in volume) by cascades of mostly machine-to-machine transactions driven by human impatience that was easy to predict a long time ago, cf. [40], does appear to be realistic, and likely inevitable. As George Gilder has said, You waste that which is plentiful, and in most wired networks bandwidth is plentiful. Wireless, though, appears to be different, as will be discussed later.

\title{
3 Voice and other missed opportunities in telecom
}

Correct technological predictions are hard in general, but telecom seems to be even worse at it than other areas. Some of the many mistakes are easy to excuse. For example, the popularity of wireless had been consistently underestimated by the industry for several decades. But this was understandable, the service was novel, and the high value that people have placed on mobility was not easy to predict. (There is a saying that you cannot tell how many people will use a bridge by counting how many swim across a river.) But others are far more surprising, and illustrate well how telecom has often "stumbled to success." As just one example, as recently as the summer of 2006, on an email discussion list, one of the top technical officers of a major U.S. cable company insisted that the idea of taking some of the bandwidth away from video services and employing it for Internet access was impractical. He insisted that "[t]he vast majority of folk in this country watch analog tv and don't have electronics to consume them digitally, don't want them or can't afford them." Yet today, Internet access is already, or is about to become, the main business of the cable networks.

The most perplexing of the many mistakes that telecom has made is in neglect of voice. Even today, voice services provide the bulk of worldwide telecom revenues, but the industry has not been paying attention. When $3 \mathrm{G}$ was being prepared for deployment around the turn of the millennium, industry was touting it as enabler of all sorts of fancy digital "content" services. But it was obvious that voice offered the greatest profit opportunities [44], and voice has indeed been the main revenue generator for $3 \mathrm{G}$. However, while the industry did benefit from this easy to anticipate but unanticipated windfall, it has neglected other 
opportunities in voice [44]. Those opportunities include voice messaging, and, perhaps most important, high quality voice. Current wireless voice quality is poor, far poorer than the "toll quality" voice standard of wired services. (And that "toll quality" is also poor, given what is possible with modern codecs.) The industry appears to have concluded from this, and the rapid expansion of wireless revenues, that the public does not care about voice quality. It is far more probable that the public accepted low quality wireless voice in order to gain mobility. But this does not mean that quality could not be sold as an added value feature. It might have provided large additional revenues and profits in the $3 \mathrm{G}$ world. There capacity was constrained, and therefore it would likely have been possible to charge extra for higher quality. As it is, HD voice, which is part of the plan for LTE, is likely to just become a standard service, as its resource requirements are low compared to capacity of the new system.

Table 2. Voice to text substitution (US).

\begin{tabular}{lrr} 
year & $\begin{array}{r}\text { voice minutes } \\
\text { billions }\end{array}$ & $\begin{array}{r}\text { texts } \\
\text { billions }\end{array}$ \\
\hline 2005 & 1,495 & 81 \\
2006 & 1,798 & 159 \\
2007 & 2,119 & 363 \\
2008 & 2,203 & 1,005 \\
2009 & 2,275 & 1,563 \\
2010 & 2,241 & 2,052 \\
2011 & 2,296 & 2,304 \\
2012 & 2,300 & 2,190
\end{tabular}

It is impossible to prove that high quality voice, if deployed and marketed properly, would have been a great success. We may obtain some indication soon from the public's reaction to HD voice in LTE. But even before that, there were a variety of reasons for believing that voice was promising, including the success if iDEN with its simple push-totalk feature. Human culture is primarily on oral one, and we have the astonishing success of the telephone to look back to, which surprised many observers by attracting far more usage and spending than postal services and the telegraph.

Those who denigrate voice can point to data such as that of Table 2. It shows steady level of voice traffic on U.S. wireless networks (based on data from [16]), which represents a decline in voice usage on a per-user basis, since the number of subscriptions has been growing during the period covered by this table. It has been surmised that this decline was due to usage migrating from voice to texting. That may very well be true, but it does not necessarily mean voice is unimportant. Texting has major advantages (in particular, 
being asynchronous, and thus less intrusive than voice), and the phenomenon shown in this table may be an indicator of a substantial opportunity in voice messaging, one that possibly could have generated good revenues in the restricted $3 \mathrm{G}$ environment.

Moving forward, the opportunity to gain additional revenues with HD voice appears to be gone, but voice should not be neglected, as it is right now, in a variety of services. Furthermore, it appears that in the development of video services, the industry is neglecting social communication in the traditional preoccupation with content.

\section{The telecom industry and innovation}

The telecom industry has repeatedly shown that it can perform well in increasing transmission capacity. It has also shown itself to be miserably poor at inventing new services. This may very well be the result of a basic cultural mismatch. The basic mission of telecom carriers is to provide ubiquitous connectivity. This is not an easy task, especially since it involves being able to respond to massive disasters, natural or man-made. Most likely the skills, mindset, and organization that can accomplish this are simply not tuned to anticipating what the capricious public will want. Even when very smart people with innovative ideas join such organizations, their initiatives tend to be blocked. From this perspective, it would be best, both for society and for their shareholders, if telcos stuck to their expertise, which is that of providing "dumb pipes." Unfortunately that is not likely to happen, as their managers (and shareholders) dream of "content" and other glamorous futures.

\section{The large telecommunications revenues}

Measuring revenues of the telecommunications sector is not simple. (For example, should one count the home WiFi access points people buy, or the cost of the WiFi equipment in a PC or tablet?) Even concentrating just on revenues of service providers presents serious problems, as various bundles mix communications with content. However, any reasonable methodology shows that telecom attracts very large revenues. Here we cite some figures from [53], which has extensive statistics (and discussion) based on data up to the year 2011. A very attractive feature is that those statistics cover all the advanced industrialized nations over about two decades, and thus provide interesting international comparisons. (It should be mentioned that other sources sometimes show different estimates. For example, for 2011, Table 3.4 of [53] shows U.S. wireless telecom revenues of $\$ 210$ billion, while CTIA, the industry association, computes it at $\$ 170$ billion for that year.) In that year, telecom revenues inside the OECD countries came to $\$ 1.35$ trillion, with U.S. accounting for $\$ 526$ billion (others sometimes cite figures as low as $\$ 350$ billion for the U.S.). Hence it seems safe to estimate worldwide telecom revenues in 2011 as being close to $\$ 2$ trillion. About half of the revenues (for OECD, and therefore likely for the whole world) comes from wireless.

For comparison, worldwide advertising spending for 2013 is projected to come to $\$ 518$ billion, so only around a quarter of telecom revenues [55]. (In the U.S. alone, advertising is more significant, as at $\$ 172$ billion it comes close to a third of telecom revenues.) Since only about $\$ 100$ billion of advertising goes into online forms, there is still plenty of room 
for Facebook, Google, and other companies to grow their ad businesses. But there is no way that the telecom business can be supported at anything like its present size by ads alone.

Yet another interesting comparison (relevant to later discussions of capital intensity) is with the electric power industry. In the U.S., total revenues from electricity sales from end users, residential as well as commercial, came to $\$ 364$ billion in 2012 (based on statistics from the U.S. Energy Information Administration). Of this amount, something like a third went to pay for fuel, so that the total amount this industry had to cover maintenance, non-fuel operations, and provide for profits and interest was only about half of what the telecom industry received.

Yet another interesting comparison is with Google. In 2012, its worldwide revenues came to just about $\$ 50$ billion. Its growth and profit rates were far higher than for most telecom service providers, but still, it commanded just $2.5 \%$ of the telecom revenue stream. So telcos will not get rich by squeezing Google alone. (Even squeezing Microsoft, with worldwide revenues of about $\$ 80$ billion per year, would be of limited help.)

A few other figures will be useful. Some key statistics of the U.S. wireless industry, drawn from [16], are presented in Table 3.

Table 3. U.S. wireless industry statistics.

\begin{tabular}{rrrl} 
year & $\begin{array}{r}\text { revenues } \\
\text { \$ billions }\end{array}$ & $\begin{array}{r}\text { capex } \\
\text { \$ billions }\end{array}$ & \\
\hline 2004 & 102.1 & 27.9 & $27.3 \%$ \\
2005 & 113.5 & 25.2 & 22.2 \\
2006 & 125.5 & 24.4 & 19.4 \\
2007 & 138.9 & 21.1 & 15.2 \\
2008 & 148.1 & 20.2 & 13.6 \\
2009 & 152.6 & 20.4 & 13.3 \\
2010 & 159.9 & 24.9 & 15.6 \\
2011 & 169.8 & 25.3 & 14.9 \\
2012 & 185.0 & 30.1 & 16.3
\end{tabular}

Thus from 2004 to 2011, the cellular industry increased its revenues by $66 \%$. The U.S. cable industry grew its revenues during that period from $\$ 60.0$ billion to $\$ 97.6$ billion, or $63 \%$ [37]. However, residential video grew just from $\$ 41.8$ billion to $\$ 56.9$ billion, or $36 \%$, and the bulk of the growth came from the "other" category (dominated by voice and Internet access), which went from $\$ 18.2$ billion to $\$ 40.7$ billion, a growth rate of $124 \%$. Content may have all the glamor, but is not where the main action is. 


\section{The high potential for profits in telecommunications}

The telecom industry has often earned very high profits. For example, the British Post Office had an extraordinarily high net profit margin of $68 \%$ in 1839 , on the eve of the Penny Post reform [41]. (This was a conscious move to tax first class letters. It served primarily as just another tax, to help pay for the general government expenses, and secondarily as a subsidy for the "content" inside newspapers, which were carried for free.) More recently, over the last few years, Carlos Slim Helú has been ranked as the richest person in the world. This resulted largely from the splendid profits of Telmex and Telcel, which enjoy dominant positions in Mexican communications, and, by most evaluations, manage to keep prices high and penetration of advanced services low in a poor country.

Monopolies have at times been very innovative, and have worked to lower costs and promote usage. The examples of the pre-1840 British Post Office and of Mexican telecom industry today (as well as many others, including many governments in recent times which milked the telecom sector to support other activities) suggest that in telecom, the incentives may not always point in that direction. Instead, short-term profit maximization can often be achieved by raising prices and limiting usage. Advocates of the Penny Post reform in Britain not infrequently promised that the increase in business from the new, lower and simpler, postage rates, would compensate for decreased revenue per letter. This did not happen, and the profits from this service declined drastically. Still, no serious attempts to go back were made, as the reform was wildly popular, both for lowering the costs of communication and for the simplicity it brought, with the complex system of distancedependent tariffs and limitations to a single sheet dispensed with.

On the other hand, the Penny Post reform did lead to a switch from a regime of static revenues to one of rapid growth. This is a phenomenon that has occurred a number of times when prices were simplified and lowered, a phenomenon that typically does not fit the economic models used to support "smart pricing," which tend to be static. While it took a quarter century, eventually British Post Office profits exceeded those attained before the Penny Post reform [41].

\section{Telco (r)evolutions}

The historical pattern, going back centuries, has been for telecommunications to grow faster than the economy as a whole [41]. That applied also at the end of the 20th century. Among the OECD countries, telecommunications revenue as a fraction of GDP increased from $2.13 \%$ in 1985 and $2.36 \%$ in 1995 to $3.58 \%$ in 2001 (Table 3.2 on p. 77 of [53]). That was the high point, though, and over the last few years it has been close to $3 \%$. One of the contemporary justifications offered for the Internet bubble was the expectations that the creation of the Internet, allowing interconnection of the growing number of computers, would yield dramatic productivity improvements, and this would stimulate increased

spending on telecom. Some analysts predicted that the fraction of GDP going to the this sector would double. It did for some countries (Korea went from 2.05\% in 1990 to 4.70\% in 2002, and was at $4.36 \%$ in 2011), but overall the growth has been far more modest. The U.S. went from $2.71 \%$ in 1995 to $4.10 \%$ in 2001 , and then down to $3.51 \%$ in 2011 . Thus it 
appears that modern economies are only willing to expand around $3 \%$ of their output on telecommunications.

What is especially intriguing is that some countries that are not just rich, but have excellent telecom infrastructures, manage to spend only modest amounts on that industry. There are some outliers (Luxembourg and Norway, in particular, with $1.2 \%$ of GDP going into telecom) that can be disregarded, since they have very high incomes per capita, so that looking at fractions of GDP conceals substantial total spending. However, Finland at $2.58 \%$ and Sweden at $1.51 \%$ (both for 2011) provide intriguing examples that deserve deeper investigations.

In addition to overall growth, there have been large additional changes inside the industry. The most obvious one is the rise of wireless. In terms of the number of people served, and the revenues and profits, it dwarfs the Internet. (It was also built primarily on the value of the low-bandwidth voice and messaging services, and until recently, the contribution of content to this growth has been negligible.) According to statistics in [53] (Table 3.4), mobile revenues accounted for $47.8 \%$ of total telecom revenues in the OECD countries in 2011, 39.9\% in the U.S., and a record high of $84.4 \%$ in Japan. (This figure for Japan is suspiciously high, as it is hard to imagine how that country could maintain and expand its wired infrastructure on just $15.6 \%$ of telco revenues that came to $2.85 \%$ of GDP in 2011. Accordingly to Table 4.1.12 in [53], in June 2012 Japan had almost half of the OECD's fiber connections, with $65 \%$ of its broadband subscribers on fiber.) Thus the share of GDP that goes to wireline has been decreasing. It appears that wired services survived largely because of a collapse in most of their costs.

In the U.S. setting, a rough rule of thumb a couple of decades ago, before the rise of the Internet, was that access, switching, and long distance each accounted for about a third of the total cost of the phone system. Today, only access is significant. This can be seen by looking at financials of two prominent companies. Level 3, especially after its absorption of Global Crossing, is universally regarded as the largest Tier-1 backbone carrier. Its share of world Internet traffic has been estimated at 10 to $20 \%$ (partially depending on how one counts its relatively new CDN business). Yet its revenues for 2012 were only $\$ 6.4$ billion. In the worldwide telecom industry with revenues of $\$ 2$ trillion (or even in the wireline sector of that industry with revenues of $\$ 1$ trillion), this is extremely small. This demonstrates that long distance transport has become very inexpensive.

The other prominent company is Akamai, the largest CDN company. It has at various times claimed to deliver up to $20 \%$ of the world Internet traffic. But its revenues in 2012 were just $\$ 1.4$ billion. Thus switching (of which Akamai has to do a lot), has also become inexpensive.

The same conclusions about the relatively low significance of long-distance transmission and switching in modern telecom can also be reached by looking at prices for Internet transit (in which large customers, whether ISPs or businesses or universities, pay for access to the Internet) or for CDN services. At current CDN prices for about $\$ 0.01$ to $\$ 0.02$ per GB (in large volumes, several petabytes per month), the whole volume of world Internet traffic, still under 50,000 PB per month in mid-2013, would cost only $\$ 6$ to 12 billion per year to deliver. 
The collapse in costs of switching and transport is what has led to the transformation of the effective architecture of the Internet documented in $[25,26]$. (The excess fiber buildout of the Internet bubble was also an enabler of this transformation.) Tier-1 carriers such as Level 3 have become much less significant, as lower-ranked ISPs have been interconnecting, and large content providers have been building out their own long-distance networks that allow them to reach the ISPs at the edges.

Various other changes have taken place, often ones that appear not to have been documented. For example, at least in the U.S., businesses used to provide a disproportionate fraction of telecom revenues through a conscious and government-sanctioned price discrimination policy. That price discrimination has disappeared, or even reversed, as enterprises are able to obtain advantageous deals in many cases.

Several conclusions appear inescapable when one considers the figures cited above. One is that with practically all costs coming from the access piece, that is (for wired services) installing and maintaining the wire to the end user, the marginal costs of carrying extra traffic are close to negligible. Hence charging according to volume of traffic cannot easily be justified on the basis of costs.

An even more fundamental implication of the new cost structure is for network engineering and management. An important goal of much of telecom research has been to devise ways to increase the engineering efficiency of the system. We now have practical applications where this was achieved [21,22]. However, the high utilization there occurred in controlled environments, with high volumes of predictable traffic, and with highly trained professional managing the network. (Something similar has happened to the backbones of the public Internet. The low utilizations that were prevailed in the late 1990, cf. [40], have been increased in many, perhaps most, networks, although there are no publicly available statistics on the subject. This was a result of more attention paid to traffic engineering, as well as slower rates of traffic growth, and slower progress in available transmission technologies.) However, on a global scale, and from the perspective of the welfare of the entire system, any efficiency gains at the core have to be balanced against the costs at the edges. Given the imbalance we have, with edge costs dwarfing those at the core, it makes sense to overprovision the core to an absurd degree in order to keep things simple (and thus inexpensive) for the users at the edges. But of course optimizations are done locally, not globally, so the temptation is always to introduce something clever that ends up hurting the system.

The final point is that the collapse of costs means that even with a diminished flow of funding for the wireline sector, it is possible to build high capacity networks. The big question is whether one can induce incumbent service providers to do so.

\section{Capital intensity}

The telecom industry frequently boasts of its high capital investments. It is also widely accepted that this industry is characterized by very high fixed capital commitments. But neither of these notions is true. For examples of truly capital intensive businesses, one needs to look at industries such as electric power, railroads, or highways. 
In the OECD countries, telecom investment as fraction of revenues was $13.9 \%$ in 2011 (Table 3.8 in [53]). U.S. wireless service providers have also been investing about $15 \%$ of their revenues in recent years, as is shown by Table 3. This has been typical also for the wireline telephone industry for the last half a century at least, with the exception of the Internet bubble years. Then investment spiked up to $27.2 \%$ of revenues for OECD as a whole. Similarly, the U.S. cellular industry invested close to $30 \%$ of its revenues in the early 2000s, during its rapid growth phase. But now it is down to the traditional telco level of about $15 \%$. That is not very high by the standards of industries that are really capital intensive.

A 2006 estimate of what is needed to maintain U.S. highways (not just the interstate system, but all major highways, but excluding local streets) at about their then level of service called for spending $\$ 223.4$ billion in 2013 (Table 2.1 of [38]). Of this amount $\$ 125.1$ billion was to be for capital expenditures (with $40 \%$ of that for additional capacity), and $\$ 98.4$ billion for operations and maintenance (ordinary repairs, snow removal, etc.). Actual expenditures have fallen short of these desiderata, but the main point is that transportation experts estimated that a healthy state of their industry required devoting $56 \%$ of the total annual expenditures to capital investments.

A good way to compare capital intensity of different industries is to look at replacement costs as compared to annual revenues. In 1913, U.S. railroads had book value of $\$ 16.6$ billion, and annual revenues of $\$ 3.2$ billion (in current dollars) [65]. Thus it would have taken 5 years of revenues to pay for the investment that went into creating that network. This comparison has to be treated with caution, in that the book value had a lot of what was then called "water" in it, so was overstated. On the other hand, book value was also understated, in that it was based on historical costs, and a brand new replacement of various lines, with the need to tear down buildings in cities that had become densely populated in the meantime, would have cost far more.

U.S. electric power industry had revenues of $\$ 364$ billion in 2012 , as was mentioned before, and of this something close to a third was accounted for by fossil fuel purchases. Hence a fairer comparison to telecom, where most of the "fuel" that provides value is generated by users, is closer to $\$ 250$ billion, or half of telecom revenues. Yet the book value of the U.S. electric power industry is around $\$ 1$ trillion. Replacement cost would likely be far higher, as the NIMBY ("not in my backyard") opposition, environmental concerns, and the like have driven costs of construction very high. An extreme example is presented by the nuclear power plants. Until recently, U.S. had 104 operational nuclear reactors that provided about $20 \%$ of the nation's electricity. While there have been promises of novel designs for nuclear reactors that would be both safe and inexpensive to build, so far none have been shown to satisfy both criteria, and current estimates of building new ones are on the order of $\$ 5$-10 billion each. Hence just replacing existing U.S. reactors would cost $\$ 500-1,000$ billion.

Compared to roads, railroads, or the electric power industry, telecom is not very capital intensive. Just one year of the OECD estimate of $\$ 526$ billion telecom revenue for the U.S. would suffice to provide a brand new infrastructure, with fiber to almost every house or business. For example, financial analysts estimate that wiring up from scratch every home 
in Kansas City with fiber would cost about $\$ 1,200$ per household [24]. At that rate, every one of the roughly 140 million households and business establishments could be covered for just $\$ 170$ billion. Of course, not every place is as easy to operate as Kansas City, but if we exclude some small proportion of the nation (and the debates are whether this is $3 \%$, $5 \%$, or $10 \%$ ), we could accomplish a complete rewiring for under $\$ 200$ billion.

In wireless, industry statistics show that cumulative capital investment, from the start of service three decades ago, came to $\$ 365$ billion by the end of 2012 [16]. Much of that investment has of course been written off, as old equipment gets replaced. So to replace everything (and it is far easier to replace telecom installations, even cell towers, than it is to replace electric power plants), would probably not cost more than half of the cumulative total, or about $\$ 180$ billion. But just to be safe, let's assume it would take $\$ 240$ billion.

When we add this up, we find that a modern telecom infrastructure for the U.S., with fiber to almost every premise, would not cost more than $\$ 450$ billion, well under one year's annual revenue. But there is no sign of willingness to spend that kind of money by the industry, even though Verizon is willing to pay $\$ 130$ billion to buy out Vodafone's share of Verizon Wireless.

Hence we can indeed conclude that modern telecom is less about high capital investments and far more a game of territorial control, strategic alliances, services, and marketing, than of building a fixed infrastructure.

\section{Mysteries of investment, costs, profits, and prices}

The relatively low capital intensity of telecommunications has to be placed in the proper context. Industrialized countries in general have been reducing their capital investments. For example, in 2012, U.S. investment came to only $16.2 \%$ of GDP, as compared to about $20 \%$ for most of the 1980s and 1990s [54]. Some sources put U.S. fixed capital formation rate even lower. For example, the World Bank reports U.S. investments at 20\% of GDP as recently as 2006, but down to $14 \%$ in 2010 and $15 \%$ in 2011 [69]. (In contrast, China's capital investments came to $46.1 \%$ of GDP in 2012 [54].)

The low capital investments in the rich economies is one of the major modern puzzles. Another one is the very high level of profits at the same time that interest rates are very low. (This phenomenon, as well as the historically abnormally high fraction of profits going to the finance sector, predates the crash of 2008 and the resulting action by monetary authorities to drive down interest rates.) Why don't entrepreneurs take advantage of those record low bond rates and compete away those abnormally high profits? (An interesting perspective is that in the 19th century, it was taken for granted that, just as basic economic logic would predict, low interest rates go together with low corporate profits. It is only in modern times that the mantra of low interest rates boosting profits has become dominant.) That would reduce the high unemployment and increase growth rates. Yet that is not happening, showing that the normal dynamics of capitalism are not operating the way theory and historical norms predict.

One worry is that a substantial part of the apparently high profits is an accounting mirage. After all, if profits can be moved around the world to escape all taxmen, so that 
even Starbucks in the UK shows up as not making any profits, while the parent company is thriving, how far can one trust any of these figures? But even if this is a factor, other statistics, such as the record lows of GDP going for wages, still present a conundrum.

An illustration of the these modern financial puzzles is provided by the valuation of Verizon Wireless. At the price of $\$ 130$ billion for the $45 \%$ share owned by Vodafone, the entire business is valued at almost $\$ 300$ billion. Yet based on the capital investment figures for U.S. wireless industry cited in the previous section, the assets of this service provider could be replaced for something like $\$ 80$ billion, a quarter of the market value. Traditionally, the Tobin Q (the ratio of market value to replacement cost) has been around 1 for most industries, and recently has been around 2. For wireless to be at twice even the elevated level found elsewhere is remarkable. It likely reflects the inertia of the system. The limited radio spectrum, multi-year contracts, and the like keep this sector locked up.

Yet another puzzle is the claim that building out fiber networks to the home is impossibly expensive. Yet at the cost of $\$ 1,500$ per household (in excess of the $\$ 1,200$ estimate of [24] for the Google project in Kansas City, were it to reach every household), and at a cost of capital of $8 \%$ (which we are told is an impossible target for state and municipal pension funds to reach), this would cost only $\$ 10$ per house per month. The problem is that managers and their shareholders expect much higher rates of return than $8 \%$ per year. One of the paradoxes is that the same observers who claim that pension funds cannot hope to earn $8 \%$ annually are also predicting continuation of much higher corporate profit rates.

Associated to the puzzle of high profits and low interest rates is the decreased relation of visible costs relevant to the ostensible provision of goods and services to the prices and profits we see in the marketplace. Thus, for example, a recent investigation by a U.S. Senate committee found that among 30 for-profit colleges, "an average of 22.4 percent of revenue went to marketing and recruiting, 19.4 percent to profits and 17.7 percent to instruction" [28]. The American for-profit higher education industry might be thought of as an outlier, in that its real business could be regarded as more to find naive and educationally unqualified people who will sign up for student loans, and less to provide real education and training. However, it is not all that unusual (and is not certain just how high the instructional spending is in the non-profit educational sector). Consider the pharmaceutical sector. The high cost of R\&D there is supposed to be driving the economics of this industry. Yet the statistics for the 19 largest pharmaceutical and biotech companies in the world showed that of their healthcare revenues of $\$ 498$ billion, $\$ 71$ billion went for R\&D, $\$ 110$ billion for profits (a mixture of figures for 2006 and 2008 from [67]), and the bulk for various other expenses.

Similarly surprising statistics occur in telecom. A recent financial analyst report estimated that for Sprint and T-Mobile, the costs of running the network in 2012 came to $31.1 \%$ and $26.7 \%$, respectively, while the costs of acquiring new customers (just selling and marketing expenses, and handset subsidies, but excluding overhead expenses, and resources devoted to retaining current customers) were $26.6 \%$ and $22.1 \%$, respectively [36].

Statistics such as those above demonstrate that the focus in our modern world is on seizing strategic bottlenecks in the economy and squeezing high profits out of them with as little investment as possible. Apple is an outstanding success at this (and so is Google). 
Apple's own R\&D expenditures are extraordinarily low for what is a shining light for technical innovation (much less than half of Nokia's R\&D spending in 2010, for example, cf. [64]). Most of the R\&D that makes Apple products attractive is performed by suppliers that have to accept very modest profits. More than that, the key advantage that Apple has now is the plethora of apps for its devices, apps built largely by independent suppliers. These app developers received $\$ 6.5$ billion over four years [59], but there are about 300,000 of these developers, so the average payout has been very modest. On the other hand, Apple has been earning each quarter more than twice in profits as much as all the app developers earned in revenue in four years ( $\$ 13.1$ billion in the fourth quarter of 2012).

It is noteworthy that initially Apple had a closed app system, and it achieved success by opening it up to outside developers, but keeping tight control.

The conclusion of this discussion is that the modern economy is full of paradoxes, and does not fit the traditional model of how capitalism is supposed to function. But in any event, it appears that service providers are reluctant to invest much, but are anxious to obtain high profits. Thus the drive for "smart pricing" is natural. On the other hand, the low marginal costs of handling actual traffic means that there is a lot of flexibility in pricing. Hence user preferences can play substantial role, no matter what management's favorite models tell them to do.

\section{A historical vignette: Bridger Mitchell and flat rates}

In evaluating prospects for various pricing plans it is useful to take a historical view, especially since this is almost never done. For instance, modern arguments in favor of "smart pricing" for data networks are nowhere near as strong as those a century ago for the voice telephone network. In those days, the industry faced high marginal costs (primarily those of the human operators involved in setting up calls), so the case for charging for calls was overwhelming in the standard model the industry used. Arguments can be made that moving to usage based pricing was instrumental in promoting the spread of telephony in large cities, cf. [23]. However, what is most remarkable is that flat rates persisted in most of the U.S. It does not appear that the industry ever tried to understand how it happened, or why they were prospering with the supposedly irrational and ruinous flat pricing model.

An excellent example of the strength of the "smart pricing" dogma is offered by by an article of Bridger Mitchell from 1978 on charging for local voice calls [34]. It was based on an earlier and more extensive Rand report issued two years earlier, acknowledged extensive comments and suggestions from numerous other researchers in the field, and was published in one of the most prestigious journals in economics. Hence it can be taken as representing the consensus of the established telecom economics community of that time.

Unlike most papers and books in this area, Mitchell did not use strongly derogatory terms for flat rates. However, a deep-seated bias against them pervades the paper. There is also a very obvious ignorance of their effects. Aside from the savings on the costs of the measurement and billing system, there is no hint that flat rates are advantageous for anyone, and it is hard not to draw the impression from the paper that they are just a cancerous sore on the body politic, and ought to be eliminated as soon as possible. 
While Mitchell did mention that "most telephone subscribers prefer flat rates," that is as far as he went. Nowhere did he mention the experiments that showed that vast majorities of people in the AT\&T experiments (and later in experiments at GTE) who were offered a choice continued with flat rates, even though it cost them more than switching to what Mitchell referred to as "usage-sensitive pricing" (USP) (also in the literature of the period often called local measured service (LMS)). Nor did he mention the analyses of the reasons for the preference. To what extent he had access to such studies is not clear. Some of the people he thanks for "comments and suggestions" were involved in the AT\&T studies, but actual publication did not come until after the Mitchell paper appeared (such as $[15,19,68]$ ). However, there was plenty of older historical evidence on telecom pricing, and that also is not mentioned.

The Mitchell paper started off with:

Although payment for nearly all other goods and services, including toll (long distance) telephone calls, increases with greater consumption, nearly 90 percent of the residential telephone subscribers and more than half the business subscribers in the United States now pay a flat monthly rate for local calls ...

Recently, however, the telephone companies and regulatory commissions have been moving cautiously towards imposing usage charges for local telephone calls....

This was then followed by a long recitation, taking up the rest of the first page, of various reasons USP was supposedly advancing or about to advance in the U.S. (With the benefit of hindsight, we can tell those reasons were not strong enough. The trend went the other way, with even long distance voice telephony moving towards flat rates.)

What was the basic justification for the move to USP? "[T] he costs of local service [had] moved upward since the late 1960's at a rate not far below the general price index." (All quotes in this section not attributed to any other source are from the Mitchell paper.) So there was not a crisis caused by surging usage, just the general pressure to avoid raising rates in a high-inflation environment that led to the Nixon wage-price freeze, which was followed by even more dramatic price escalation. On the other hand, "technological advances [had] benefited long distance far more than local telephone calling." And what were the advances that Mitchell cited? "Development in microwave communications, coaxial cable, satellites, and waveguides." Certainly all these contributed to lowering costs of providing phone service. What is interesting is Mitchell listed only advances in transmission, and said nothing at all about switching. Electronic switching systems were advancing rapidly by the mid-1970s. The Bell System introduced the 1ESS switch a decade earlier, for example. With the ongoing and widely recognized advances in computing technologies, it should have been obvious that switching costs would decline dramatically (even if they had not at that point), and that this would apply to local as well as long distance telephony. Mitchell was not unaware of electronic switching, as in discussing the costs of metering local calls, he did mention that such costs were much lower in local offices with electronic exchanges than in those with electro-mechanical ones, which made USP more attractive. But he completely ignored the effect of the new technologies on the basic costs of switching, and thus of providing voice services. 
The one cost element that was clearly not going to decline to any appreciable extent was local transmission, which meant primarily maintenance of the copper wire from the local central office to the customer. This was the 1970s, long before the era of the Internet or the various online computer services, and before PCs started penetrating households in any numbers. Hence only voice services were of interest to regulators, legislators, and the public. So the link to the home was expected to continue as a copper wire. And the costs of installing and maintaining that copper were almost completely independent of usage. Hence all the discussion about advantages of USP in Mitchell's paper ignored the vital point that the one component of costs of service that could not be appreciably reduced would not be affected by switching to USP.

Mitchell noted that "[a] welfare analysis of two-part tariffs requires knowledge of demand at different prices." However, "no data are available as yet on calling rates under usage-sensitive pricing," so he proceeded to make a variety of assumptions (which he admitted were simplified). Some of the questionable features of those assumptions will be noted below. However, this is not a careful review of his paper, so not everything is examined. The point is just to point out some of the more strikingly peculiar features of his work.

Mitchell decided to "[ignore] ... the dynamic effects of the number of subscribers in the telephone network on the value of service to any one subscriber." Today, it appears to be widely understood that the number of users is extremely important in determining value, especially for new products and services. This is shown, for example, by the frequent invocations of Metcalfe's Law, which does convey the message about the value of connectivity, even though though there are serious arguments that its quantitative form is incorrect [11]. Interestingly enough, the first modern studies of network effects were carried out inside the phone industry by Jeff Rohlfs [57] some years before Metcalfe formulated his "Law" and before Mitchell wrote his paper. Still, as Mitchell explained, ignoring this effect was not unreasonable for voice telephony in the U.S. in the 1970s, where this service had achieved an almost complete penetration. He did cite some published papers that had considered the influence of this effect on the early development of the telephone system.

What Mitchell did not say, but was implicit in his analysis, is that he was also ignoring the intensity of usage as a determinant of value. This is now widely recognized as important. Financial analysts, investors, and the press cite figures from social networks, say, or from more neutral outside monitoring organizations such as comScore about the average length of time that users spend on those networks. The big change in this perception, that heavy usage increases value, took place in the early days of the Internet bubble, when AOL, then the dominant online service provider, switched from metered rates to flat ones [41]. Management resisted the move, and was only induced to make it by competition, as it feared (correctly) that the time spent online would jump. But once they moved to the new environment (assisted by improvements in technology, as well as presence of competitive local service providers who were able to lease modems for the AOL dial service at more affordable rates than the ILECs had charged), they came to appreciate the value of intensity of usage, and proudly hailed measures showing its was increasing. But that was two decades later, so one cannot fault Mitchell too much for ignoring it, as there were not many examples 
of this effect playing a major role in telephony in his time. On the other hand, there was extensive historical evidence of such effects, going back to the early days of postal services. An interested researcher could easily have discovered this.

Overall, Mitchell's models are simplistic, but that is of necessity true of all economic models. Still, even given the low level of complexity that Mitchell limited himself to, there are many questionable aspects of his work. For example, there is little analysis of the sensitivity of the results to basic assumptions. (This can be excused to some extent, of course, since this was before the era of wide spread of desktop PCs and spreadsheets, so such calculations were not as easy to perform then as they are today.) In particular, Mitchell did not exhibit any combination of basic parameters for his model under which flat rates are optimal. Yet such must exist. The logic of bundling (clearly understood to merchants since time immemorial, and explicated in the economics literature in the 1960s and visible in Fig. 1 of Mitchell's paper) argues that for some parameters flat rates provide higher profits for service providers.

The strangest omission on Mitchell's part was of the basic comparison of U.S. and foreign volumes of usage. He allowed that one should do some real studies of the effects of USP. He also wrote that "new insights for U.S. practice could be gained from a comparative analysis of the telephone pricing and demand experience of foreign utilities that have long operated with various forms of measured service." (Note that what he regarded as potentially valuable were just the lessons about applying USP, an indication of the deep bias against flat rates.) And earlier he cited briefly some Norwegian experiences with peakload pricing. But nowhere did he even hint at the most salient difference between U.S. and the rest of the world in the 1970s, namely that daily usage of a phone line was about three times higher in the U.S. than in the rest of the world (see [41] for data and references). This dramatic difference (especially when combined with a look at revenues of telcos in different countries) cast doubts on various of Mitchell's estimates of marginal costs, as well as his assumptions about marginal utilities and about the effects that USP might have on usage.

Another major issue, although one probably inevitable given the kinds of economic models that Mitchell relied on, was the static nature of his analysis. Consumers were supposed to have certain willingness to spend, and once prices were changed, they would adjust quickly and settle into a new equilibrium usage pattern. Yet what we observe in practice is that changes in pricing lead not only to an instantaneous response, but also to changes in long-term growth rates. This occurred when AOL introduced flat rates in 1996. There was a quick jump, followed by vigorous growth, as opposed to static level of usage under metered rates. Earlier, the same phenomenon took place with the introduction of the Penny Post in Britain in 1840, as well as with the drastic lowering of taxes on newspapers in 1836 [51].

In justice to the many researchers in the telecommunications economics community it should be said that there were some papers that did consider some of the long-range effects. Particularly noteworthy was the work of Jeff Rohlfs [57] on network effects. Also, about the time that the Mitchell paper [34] appeared, results from the AT\&T and GTE experiments with metered local rates were becoming available, and so the awareness of the 
limitations of the consensus view was becoming wider. But this consensus view continued, and continues, to dominate.

\section{Another historical vignette: Flat rates for data}

Another interesting historical vignette is the advocacy of flat rates for data services by Loretta Anania and Richard Jay Solomon. They were among the early pioneers researching pricing of broadband services, in the days of ISDN and ATM $[3,4,5]$. They also appear to have been unique in that community in arguing for flat rates. Furthermore, they had very good arguments, based on excellent insights into data networks, in particular about the lack of direct relation between volume and value of data transfers.

There are at least two interesting aspects to the work of Anania and Solomon. One is the very limited impact it has had, as measured in citations. This appears to reflect the strong bias in favor of "smart pricing." The other interesting aspect of Anania's and Solomon's work is the limited range of arguments they presented, which reflects the lack on studies of flat rates. Their early arguments for flat rates were basically limited to pointing out that users would have large opportunities to bypass service provider controls [4]:

... dynamic allocation of network resources will become increasingly difficult for the carrier (or regulator) to track. So, with integrated digital networks, the flat-rate, or pay-in-advance subscription solution, may be the best method of pricing.

Later, they began to mention user preferences, but without much emphasis or detail [5]. This can again be taken as an indication of how little attention has been paid historically to flat rates. This tradition continues. One can cite a variety of recent papers, such as [8,39], that fail to address many of the key advantages of flat rates.

Given all these precedents, it appears inevitable that the industry, and the networking research community, will continue to press for "smart pricing." As will be explained later, there are reasons to doubt whether they will be very successful. However, to the extent they are, it appears they are neglecting some important aspect of implementing "smart pricing."

\section{Directions for smart pricing research and deployment}

Current research directions on smart pricing are probably not optimal for influencing applications. Most of the work appears to be inspired by the desire to control congestion, and to maximize the engineering efficiency of networks. However, engineering efficiency was seldom the main driving force behind telecom pricing in the past, and it is not now. Far more important has been the incentive to maximize revenues through price discrimination. While the basic incentives and practices of price discrimination are ancient, they were first explicated by the French "econo-engineers" of the middle of the 19th century [18]. Their work was motivated by the desire to understand business policies of the most revolutionary industry of that era, namely railroads. There is a memorable and oft-quoted 1849 passage on this subject by Jules Dupuit [17]: 
It is not because of the few thousand francs which would have to be spent to put a roof over the third-class carriages or to upholster the third-class seats that some company or other has open carriages with wooden benches. ... What the company is trying to do is to prevent the passengers who can pay the second-class fare from traveling third class; it hits the poor, not because it wants to hurt them, but to frighten the rich. ... And it is again for the same reason that the companies, having proved almost cruel to the third-class passengers and mean to the second-class ones, become lavish in dealing with first-class passengers. Having refused the poor what is necessary, they give the rich what is superfluous.

This description is not an exaggeration. In fact, many railroads did not have any seats in third-class carriages. Some refused to run any third-class carriages, and among those that did, such carriages went by special trains that were slow and ran at inconvenient times. Thus not only was "versioning" common, so was a form of what is now called "damaged goods" practice, where extra costs were incurred in order to offer an inferior service at a lower price. A contemporary account claimed that "the humbler order of passengers will not easily forget that a [railway] director once proposed to hire a number of chimney-sweeps to render-what, with the best company, are nothing better than locomotive hutches-perfectly untenable" [6]. (It should be said that no evidence has been found that any chimney-sweeps were actually hired to make third-class travel less attractive. This was just a suggestion, but a very revealing one in explaining the motivations driving many policy decisions.)

The incentives that drove railroad managers to versioning and damaged goods have also been present in telecommunications. One of the fundamental obstructions to the introduction of either fundamentally new networking technologies, or of sophisticated pricing for the current ones, is that, in a slight paraphrase of Scott Bradner's memorably pithy quote [10],

The Internet is not reliably bad enough to drive the creation of a new network.

But that could be changed through "damaged goods" practices. "Buffer-bloat," which is now an accidental impairment on many networks, could be introduced systematically. Various types of noise or artificial packet drops (coupled with Deep Packet Inspection and statistical profiling, as is already done in various traffic-shaping practices) could be introduced much more widely. For example, since the most valuable types of communication tend to use little bandwidth (as will be discussed in more depth later), and voice is very latency-sensitive, artificial increases in latency could decrease the quality of VoIP services. If smart pricing is to spread, there should be far more research on such approaches, and they should be part of the standard networking courses.

There is also too little research on bamboozling customers. The financial analyst Craig Moffett and his colleagues noted that "[f] or years, the telecom industry has thrived on obfuscation" [35]. Even earlier, back in 1998, Scott Adams in one of his Dilbert books talked of phone companies that "form confusopolies to make it impossible for the average individual to determine who has the lowest price," [2], p. 161. Furthermore, there is now solid quantitative research that demonstrates the effectiveness of confusing users with complex pricing plans [32]. Hence this feature of complicated pricing deserves more attention both in research programs and in the education of students for the workplace. 


\section{Growth in demand}

To evaluate prospects of various pricing schemes, we have to consider the balance of demand and supply of data transport.

Wireline traffic growth has been decelerating over the last few years, and is now taking more than two years to double. This is shown by the mostly widely cited project to estimate and predict traffic growth, Cisco's Visual Networking Index (VNI) [13]. The May 2013 VNI report projects that the traffic on the wired Internet will grow only $25 \%$ from 2012 to 2013 , and will have a compound growth rate of $21 \%$ from 2012 to 2017 . The sources for the VNI studies are confidential, though, and there are some estimates of growth rates that are somewhat higher than those of VNI.

Here we cite some public data that generally support the VNI observations. (References and URLs are available at [33].) The European IX association reports their aggregate peak traffic growth has declined from 57\% in 2008 to $45 \%$ in 2012. TeleGeography estimates that the "[g] rowth in worldwide international Internet capacity declined from $63 \%$ in 2009 to $33 \%$ in 2013," [63]. Australia is an outlier among industrialized countries in that it is still maintaining a high growth rate, at 59\% during the year ended June 2013, just about the same as the annual compound rate of $60 \%$ over the previous four years. However, Australia's Internet traffic per capita is still only about half that of the U.S.

The most intriguing outlier in the available statistics is Japan. It has the most advanced infrastructure in the world, in terms of fraction of wireline broadband subscribers who have fiber. Along with Hong Kong and South Korea, it usually shows up at the top of rankings by effective speed of connections. Yet Japanese Internet traffic is relatively low, and is growing slowly. The latest measurement from the remarkable cooperative industry effort, covering about $40 \%$ of the Japanese market (see [33]), taken in May 2013 and kindly provided by Kenjiro Cho (see also [12] for earlier but more detailed summary) shows a continuation of the $20-25 \%$ annual growth rate of wireline traffic that has prevailed over the last half a dozen years.

In wireless, the calls for urgent action to deal with the perceived spectrum shortage were and continue to be fueled by reports and predictions of data traffic more than doubling each year (cf. [66], p. 76 and [1,56]).

In Australia, the data downloaded to mobile handsets grep $43 \%$ from the 4 th quarter of 2012 to the 2 nd of 2013, an annual rate of $105 \%$. However, in the U.S., the growth of $123 \%$ from 2010 to 2011 moderated to $69 \%$ in the following year. The Cisco VNI of May 2013 projects a $66 \%$ annual growth rate of mobile data between 2012 and 2017. While this is a substantial decline from earlier VNI projections, it is doubtful whether even that rate can be sustained for long, as will be discussed in the next section.

While growth rates for wireless traffic far exceed those for wireline, it is important to remember that total volumes of data transmitted by mobile wireless technologies (so excluding WiFi) are still low. For both Australia in mid-2013 and the U.S. for year-end 2012 , they were under $3 \%$ of total Internet traffic for those countries. Thus the potential demand just from people switching their usage from wireline to wireless is huge. 


\section{Technology trends}

The three main ingredients of the ICT (information and communication technologies) industry are computing, storage, and communication. They have all been riding the Moore's Law curve, with relatively steady and relatively predictable rates of improvement. (See [33] for some statistics and references.) Those rates have declined, but over the last few years, the amount of raw computing, or raw storage, or basic photonic transmission that can be performed for a unit cost has been doubling about every two years. While there have always been fears that progress might grind to a halt, that has not happened, even though there are various indications of slowdowns. But perhaps even more important than a general slowdown is that locality is becoming more pronounced. While magnetic storage densities are still increasing rapidly, the bandwidth to disks is growing much more slowly. Similarly, much of the improvement in raw computing power is now coming from putting more cores on a chip, but the bandwidth to the chip is an increasingly important barrier to the utilization of that power. Thus in both computing and storage, data moves less, or, as the database community has been saying for a long time, is becoming "cooler."

The arrival of the Internet led to a dramatic jump in data traffic in the mid-1990s, when for a while there actually was the "Internet traffic doubling every 100 days" phenomenon. This was followed by several years of doubling every year. However, for most of the last decade, worldwide Internet traffic growth has been decelerating, as discussed in the previous section. It is not impossible that it may fall substantially below the level of growth in computing power and storage, as has been predicted by the Cisco measurement and forecasting effort [13], especially since that has happened in Japan.

On the other hand, the volumes of either broadcast video or of magnetic disk storage dwarf the Internet's transmission capacity. Thus should masses of people suddenly "cut the cord" and attempt to obtain their favorite TV programs over the Internet, networks would collapse under the load. However, there is no sign of that happening, the switch to the more natural mode of on-demand viewing is proceeding fairly slowly (facilitated by kludgy half-way solutions such as video recorders). Similarly, there is great promise in machine-to-machine communication, but it is also arriving at a measured pace. Therefore wireline networks do have an incentive to encourage innovative uses of their facilities. This incentive is especially important because of the competition from wireless. As we have discovered over the last three decades, mobility is extremely attractive. Both usage and investment are moving towards wireless, and if application developers concentrate their energies on the low traffic, small screen size, and low power mobile devices, wireline could become a backwater.

As for mobile wireless, it is very difficult to estimate the growth of transmission capacity, because there are so many technological and economic dimensions to this problem. Currently, the shift to $4 \mathrm{G}$ and LTE offers a quantum jump in data capacity. However, beyond that, the possible improvements in modulation and related approaches appear to be rather limited. The industry is aiming for a 1000x boost, and while it usually does say that the time frame for this jump in traffic is impossible to predict, it does cite prominently the recent $2 \mathrm{x}$ annual growth rates, cf. [1,56]. It appears very unlikely that even $50 \%$ per year growth rates could be maintained for long. 
Note that one of the favorite routes to increasing capacity, namely assigning more spectrum for mobile wireless, can offer only limited relief. The National Broadband Plan released by the Federal Communications Commission in March 2010 reports that the U.S. currently has 547 megahertz that can be used for such purposes, and calls for doubling that within 10 years [66]. However, such a doubling would only compensate for one year of $100 \%$ annual growth, and of two years of $50 \%$ annual growth.

Substantial improvements in capacity could be achieved just by building more facilities, but that would require greatly increased capital spending. That could come from either higher revenues from users, or from restructuring the industry so it spends less on marketing, lobbying, and other activities, and more on construction. Since neither is likely to happen, we are likely to see traffic limited by available capacity. Combined with the wide disparity of various types of bits, this suggests that pricing will play a significant role in balancing demand and supply.

For wired networks, the capacity limitations of mobile wireless, as well as the "mental transactions costs" that are likely to be imposed by pricing, leave a substantial opening. However, to exploit their advantage, they will need to encourage use, and that argues for the simplest possible pricing, which is flat rate.

\section{Conclusions}

As technology advances, implementing "smart pricing" is becoming easier. Further, the deep (and irrational) prejudice in favor of "smart pricing" will likely drive the industry and academic researchers to continue pursuing a variety of schemes, some to the point of deployment.

At the same time, general technology advances are complicating life, and intensifying users' desire for simplicity. In the wireline arena, we find rapid improvements in transmission capacity, and relatively slow growth in demand from consumers. This creates incentives for service providers to stimulate usage, and thus argues for flat rates and simple networks, with large pipes, with any market segmentation determined by the size of the pipe.

In wireless, technology improvements are slower, and likely demand growth faster. Thus in this area pricing is likely to play a larger role. But the human desire to avoid "mental transaction costs" will still argue for simplicity, at least at individual consumer level.

There may well be more sophistication at the business to business level, when companies contract with service providers to provide certain transmissions in ways invisible to consumers, just as today Amazon sells ebooks with the wireless delivery achieved seamlessly by an established carrier. The arguments for simplicity are not as important at the business-to-business level as it is with consumers, since companies come closer to the economic rationality so beloved by experts. However, it is not clear whether "smart pricing" will spread far even there, since managers appear to much prefer strategic games to real market. Furthermore, the example of Apple's app store shows that even at the level of businesses, there are advantages to simplicity. 


\section{Acknowledgements}

This paper was prepared with the partial support of DARPA contract FA8750-13-2-0023 on "The evolution of control plane resilience."

\section{References}

1. 4G Americas, Meeting the 1000x Challenge: The Need for Spectrum, Technology and Policy Innovation, white paper, October 2013. Available at 〈http://www.4gamericas.org/documents/2013_4G

2. S. Adams, The Dilbert Future: Thriving on Business Stupidity in the 21st Century, HarperCollins, 1998.

3. L. Anania and R. J. Solomon, "User arbitrage and ISDN," InterMedia, Jan. 1988, pp. 2531.

4. L. Anania and R. J. Solomon, "Models of network infrastructure: Pricing ISDN for access," in J. H. Alleman and R. D. Emmerson, eds., Perspectives on the Telephone Industry: The Challenge for the Future, Harper \& Row, 1989, pp. 287-303.

5. L. Anania and R. J. Solomon, "Flat-The minimalist price," in L. W. McKnight and J. P. Bailey, eds., Internet Economics, MIT Press, 1997, pp. 91-118.

6. Anonymous, "Railway comfort," Household Words: A Weekly Journal Conducted by Charles Dickens, Aug. 3, 1850, pp. 449-450.

7. Anonymous, "Let Mexico's moguls battle," Economist, Feb. 4, 2012.

8. J. M. Bauer and S. S. Wildman, "The economics of usage-based pricing in local broadband markets," NCTA white paper, Dec. 2012, $\langle$ http://i.ncta.com/ncta_com/PDFs/Wildmanreport_web.pdf $\rangle$.

9. K. Bode, "Cable industry finally admits caps not about congestion after insisting for years caps were about congestion," DSL Reports, Jan. 17, 2013. 〈http://www.dslreports.com/shownews/Cable-Industry-Finally-Admits-Caps-NotAbout-Congestion-122791〉.

10. S. Bradner, "Will there be a next-generation network?," Network World, July 21, 2003. 〈http://www.networkworld.com/columnists/2003/0721bradner.html〉.

11. B. Briscoe, A. Odlyzko, and B. Tilly, "Metcalfe's Law is wrong," IEEE Spectrum, July 2006, pp. 26-31. Available at 〈http://www.spectrum.ieee.org/jul06/4109〉.

12. K. Cho, "Broadband traffic report: Traffic trends over the past year," Internet Infrastructure Review, vol. 16, August 2012, pp. 33-37. Available at 〈http://www.iij.ad.jp/en/company/development/iir/pdf/iir_vol16_report_EN.pdf).

13. Cisco Visual Networking Index, 〈http://www.cisco.com/en/US/netsol/ns827/networking_solutions_sub_solution.html〉.

14. R. N. Clarke, "Costs of neutral/unmanaged IP networks," Review of Network Economics, vol. 8, no. 1, March 2009. Preprint available at $\langle$ http://ssrn.com/abstract $=903433\rangle$.

15. J. G. Cosgrove and P. B. Linhart, "Customer choices under local measured telephone service," Public Utilities Fortnightly, Aug. 30, 1979, pp. 27-31. 
16. CTIA - The Wireless Association, Semi-Annual Year-End 2012 Top-Line Survey Results, 〈http://files.ctia.org/pdf/CTIA_Survey_YE_2012_Graphics-_FINAL.pdf $\rangle$.

17. R. B. Ekelund, "Price discrimination and product differentiation in economic theory: An early analysis," Quarterly Journal of Economics, vol. 84, no. 2, 1970, pp. 268-278.

18. R. B. Ekelund, Jr., and R. F. Hébert, Secret Origins of Microeconomics: Dupuit and the Engineers, Univ. Chicago Press, 1999.

19. L. Garfinkel and P. B. Linhart, "The transition to local measured telephone service," Public Utilities Fortnightly, Aug. 16, 1979, pp. 17-21.

20. L. Garfinkel and P. B. Linhart, "The revenue analysis of local measured telephone service," Public Utilities Fortnightly, Oct. 9, 1980, pp. 15-21.

21. C.-H. Hong, S. Kandula, R. Mahajan, M. Zhang, V. Gill, M. Nanduri, and R. Wattenholer, "Achieving high utilization with software-driven WAN," ACM SIGCOMM 2013, 〈http://conferences.sigcomm.org/sigcomm/2013/papers/sigcomm/p15.pdf .

22. S. Jain, A. Kumar, S. Mandal, J. Ong, L. Poutievski, A. Singh, S. Venkata, J. Wanderer, J. Zhou, M. Zhu, J. Zolla, U. Hölzle, S. Stuart, and A. Vahdat, "B4: Experience with a globally-deployed software defined WAN," ACM SIGCOMM 2013, 〈http://conferences.sigcomm.org/sigcomm/2013/papers/sigcomm/p3.pdf $\rangle$.

23. R. R. John, Network Nation: Inventing American Telecommunications, Harvard Univ. Press, 2010.

24. C. Kirjner and R. Parameswaran, "Google Fiber - How much will Google spend to overbuild Kansas City? How much would it cost to expand?," BernsteinResearch report, April 8, 2013.

25. C. Labovitz, S. Iekel-Johnson, D. McPherson, J. Oberheide, F. Jahanian, and M. Karir, ATLAS Internet Observatory 2009 Annual Report, available at 〈http://www.nanog.org/meetings/nanog47/presentations/Monday/

Labovitz_ObserveReport_N47_Mon.pdf $\rangle$.

26. C. Labovitz, S. Iekel-Johnson, D. McPherson, J. Oberheide, and F. Jahanian, "Internet inter-domain traffic," ACM Computer Communication Review, Oct. 2010, pp. 75-86. Available at 〈http://www.sigcomm.org/sites/default/files/ccr/papers/2010/October/18512751851194.pdf $\rangle$.

27. D. Levinson and A. Odlyzko, "Too expensive to meter: The influence of transaction costs in transportation and communication," Phil. Trans. Royal Soc. A, vol. 366, no. 1872, 2008, pp. 2033-2046. Preprint available at $\langle$ http://ssrn.com/abstract $=1735657\rangle$.

28. T. Lewin, "Senate committee report on for-profit colleges condemns costs and practices," New York Times, July 30, 2012.

29. D. Lyons, "Internet policy's next frontier: Data caps, tiered service plans, and usagebased broadband pricing," Federal Communications Law Journal, vol. 66, no. 1, 2013, to appear. Preprint available at 〈http://ssrn.com/abstract=2239921 $\rangle$.

30. S. Marek, "AT\&T's Stephenson: Content players will subsidize consumer's data," FierceWireless, May 15, 2013, 〈http://www.fiercewireless.com/story/atts-stephensoncontent-players-will-subsidize-consumers-data/2013-05-15〉. 
31. S. McCartney, "Flier auctions: Better seats, going once, going twice ...," Wall Street Journal, April 25, 2013.

32. M. Miao and K. Jayakar, "Bounded rationality and consumer choice: An evaluation of consumer choice of mobile bundles in China." Preprint available at $\langle$ http://ssrn.com/abstract $=2241581\rangle$.

33. MINTS, Minnesota Internet Traffic Studies project. Available at $\langle$ http://www.dtc.umn.edu/mints/〉.

34. B. M. Mitchell, "Optimal pricing of local telephone service," American Economic Review, vol. 68, no. 4, Sept. 1978, pp. 517-537.

35. C. Moffett, N. Del Deo, and A. Chan, "Quick take - AT\&T (T): Market share(ing) Part II ... A quieter voice," BernsteinResearch report, July 18, 2012.

36. C. Moffett and N. Del Deo, "Sprint: How long is long-term?," MoffettNathanson Research report, Oct. 11, 2013.

37. National Cable \& Telecommunications Association, cable industry revenue 1996 - 2011 , 〈http://www.ncta.com/Stats/CustomerRevenue.aspx〉. Downloaded Sept. 28, 2012.

38. National Cooperative Highway Research Program (NCHRP), Future Dinancing Options to Meet Highway and Transit Needs, Dec. 2006. Available at 〈http://onlinepubs.trb.org/onlinepubs/nchrp/nchrp_w102.pdf $\rangle$.

39. A. Nevo, J. L. Turner, and J. W. Williams, "Usage-based pricing and demand for residential broadband," preprint, Sept. 2013. Available at $\langle$ http://ssrn.com/abstract $=2330426\rangle$.

40. A. Odlyzko, "The current state and likely evolution of the Internet," Proc. Globecom'99, IEEE, 1999, pp. 1869-1875. Preprint available at 〈http://www.dtc.umn.edu/ odlyzko/doc/globecom99.pdf $\rangle$.

41. A. M. Odlyzko, "The history of communications and its implications for the Internet," 2000 unpublished manuscript, available at $\langle$ http://ssrn.com/abstract $=235284\rangle$.

42. A. M. Odlyzko, "Content is not king," First Monday, vol. 6, no. 2, February 2001, http://firstmonday.org/htbin/cgiwrap/bin/ojs/index.php/fm/article/view/833/742.

43. A. M. Odlyzko, "Internet pricing and the history of communications," Computer Networks, vol. 36, 2001, pp. 493-517. Preprint available at $\langle$ http://ssrn.com/abstract $=235283\rangle$.

44. A. M. Odlyzko, "Talk, Talk, Talk: So who needs streaming video on a phone? The killer app for 3G may turn out to be-surprisevoice calls," Forbes, August 20, 2001, p. 28. Preprint available at 〈http://www.dtc.umn.edu// odlyzko/doc/3g.accidental.success.txt $\rangle.$

45. A. M. Odlyzko, "The many paradoxes of broadband," First Monday, vol. 8, no. 9, 2003. 〈http://firstmonday.org/htbin/cgiwrap/bin/ojs/index.php/fm/article/view/1072/992〉.

46. A. M. Odlyzko, "Telecom dogmas and spectrum allocations," 2004 paper written for the Wireless Unleashed blog, 〈http://www.dtc.umn.edu/ odlyzko/doc/telecom.dogmas.spectrum.pdf $\rangle$.

47. A. M. Odlyzko, "The evolution of price discrimination in transportation and its implications for the Internet," Review of Network Economics, vol. 3, no. 3, September 2004, pp. 323-346. Preprint available at 〈http://ssrn.com/abstract $=596301\rangle$. 
48. A. M. Odlyzko, "Threats to the Internet: Too much or too little growth?," Internet Evolution, Feb. 25, 2008, 〈http://www.internetevolution.com/author.asp?section_id=592\&doc_id=146747\& $\rangle$.

49. A. M. Odlyzko, "The delusions of net neutrality," Telecommunications Policy Research Conference, 2008, 〈http://www.dtc.umn.edu// odlyzko/doc/net.neutrality.delusions.pdf $\rangle$.

50. A. M. Odlyzko, "Network neutrality, search neutrality, and the never-ending conflict between efficiency and fairness in markets," Review of Network Economics, vol. 8, no. 1, March 2009, pp. 40-60. Preprint available at 〈http://ssrn.com/abstract $=1095350\rangle$.

51. A. M. Odlyzko, "The volume and value of information," International Journal of Communication, vol. 6, 2012, 〈http://ijoc.org/ojs/index.php/ijoc/article/view/1570/740〉.

52. A. Odlyzko, B. St. Arnaud, E. Stallman, and M. Weinberg, Know Your Limits: Considering the Role of Data Caps and Usage Based Billing in Internet Access Service, Public Knowledge, 2012. Available at /http://publicknowledge.org/files/UBP

53. OECD, OECD Communications Outlook 2013, 〈http://www.oecd-ilibrary.org/science-and-technology/oecd-communications-outlook2013_comms_outlook-2013-en $\rangle$.

54. T. Orlik, "Beijing falls short on rebalancing," Wall Street Journal, May 23, 2013.

55. Plunkett Research, Advertising \& Banding Industry Overview, 〈http://www.plunkettresearch.com/advertising-branding-market-research/industrystatistics $\rangle$. Downloaded Sept. 26, 2013.

56. Qualcomm, Inc., The 1000x Mobile Data Challenge: More Small Cells, More Spectrum, Higher Efficiency, July 25, 2013 presentation deck. Available at 〈http://www.qualcomm.com/media/documents/tags/1000x-challenge〉.

57. J. Rohlfs, "A theory of interdependent demand for a communications service," Bell Journal of Economics and Management Science, vol. 5, 1974, pp. 16-37.

58. S. Sen, C. Joe-Wong, S. Ha, and M. Chiang, "A survey of broadband data pricing: Past proposals, current plans, and future trends," to be published. Preprint available at $\langle$ http://arxiv.org/pdf/1201.4197v2.pdf $\rangle$.

59. D. Streitfeld, "As boom lures app creators, tough part is making a living," New York Times, Nov. 18, 2012.

60. B. Swanson, "The coming exaflood," Wall Street Journal, Jan. 20, 2007.

61. B. Swanson and G. Gilder, "Estimating the exaflood," Discovery Institute white paper, Jan. 29, 2008, 〈http://www.discovery.org/a/4428〉.

62. N. Szabo, "The mental accounting barrier to micropayments," 1996 white paper, $\langle$ http://szabo.best.vwh.net/micropayments.html $\rangle$.

63. TeleGeography, "Europe emerges as global Internet hub," Sept. 18, 2013 press release, 〈http://www.telegeography.com/products/commsupdate/articles/2013/09/18/europeemerges-as-global-internet-hub/ $\rangle$.

64. A. Troianovski and S. Grundberg, "Nokia's bad call on smartphones," Wall Streen Journal, July 19, 2012.

65. U.S. Department of Commerce, Bureau of the Census, Historical Statistics of the United States: Colonial Times to 1970, 1975. 
66. U.S. Federal Communications Commission, Connecting America: The National Broadband Plan, March 2010, available at 〈http://download.broadband.gov/plan/nationalbroadband-plan.pdf $\rangle$.

67. Wikipedia for the pharmaceutical industry, 〈http://en.wikipedia.org/wiki/Pharmaceutical_industry . Downloaded Oct. 7, 2013.

68. T. F. Wong, "Identifying tariff induced shifts in the subscriber distribution of local telephone usage," in L. Courville, A. de Fontenay, and R. Dobell, eds., Economic Analysis of Telecommunications: Theory and Applications, North-Holland, 1983, pp. 263-278.

69. World Bank, Gross fixed capital formation (\% of GDP), interactive table at 〈http://data.worldbank.org/indicator/NE.GDI.FTOT.ZS〉, downloaded May 27, 2013. 